\title{
scripted
}

Volume 12, Issue 2, December 2015

\section{HEALTH LAW AND CROSS BORDER HEALTH CARE IN EUROPE: 2015 CONFERENCE OF THE EUROPEAN ASSOCIATION OF HEALTH LAW}

\author{
Leslie Stevens ${ }^{*}$
}

DOI: $10.2966 /$ scrip.120215.176

\section{(c) (1) (8)}

EY NO NO C Leslie Stevens 2015. This work is licensed under a Creative

Commons Attribution-NonCommercial-ShareAlike 4.0 International License. Please click on the link to read the terms and conditions

\footnotetext{
* Research Fellow, Administrative Data Research Centre - Scotland, PhD candidate and PhD Convener, the Mason Institute, School of Law, University of Edinburgh.
} 
The city of Prague was the historic backdrop for the fifth instalment of the European Association of Health Law's (EAHL) conference on cross border health care in Europe. ${ }^{1}$ Taking place over the $1^{\text {st }}$ and $2^{\text {nd }}$ of October 2015, the fifth EAHL conference was its first to cross borders into Eastern Europe, attracting delegates from across Europe and further afield, including Nigeria, South Africa and the US. The conference programme was developed around the theme of delivering cross border health care with presentations speaking to the various component pieces needed to deliver care in an increasingly interconnected environment.

The keynote addresses, delivered on each of the two days of the conference, communicated the crucial but differing perspectives on cross border health care. Delegates were presented with the difficulties faced by national health services who continue their attempts to deliver better quality health care in an increasingly resource-strapped and shifting regulatory environment, complicated by the implications of a mobile patient citizenry for unplanned health care. The other keynotes offered the perspectives of both regulator and the patient, posing questions as to how the introduction of Directive 2011/24/EU ("on the application of patients' rights in cross border health care") might facilitate better care in the cross border setting but also transform our beliefs and expectations as to patient rights. What is clear is that much is still to be hoped for only two years after the 2013 deadline for transposition of the Directive. Further (and much clearer) communication with individuals as to their rights, especially for reimbursement, must be initiated; clarity must be sought on issues surrounding pre-authorisation and administrative burdens must be alleviated across Member States where possible. Improvements in these areas could contribute to further successes in delivering better patient outcomes when and if the need for cross border care arises.

The academic programme was divided into parallel sessions according to themes that reflected the many component parts involved in the delivery of cross border health care: patient rights to privacy, access to clear, relevant and adequate information, current inequities in access to quality health care; regulatory and administrative barriers to the delivery of care; negotiation of the commercial elements of cross border health care; and managing developments in technology and regulation that stand to positively or negatively impact the delivery of cross border care. The sessions offered an interesting survey of experiences in delivering cross border care across Member States and further afield (e.g. in the US) but many talks spoke broadly to the most critical of legal, ethical and practical issues currently arising in health care.

Across both days, there was a strong focus on the implications of cross border care for patient rights, especially, the implications for protecting informational privacy. Four members of the JK Mason Institute, based at the University of Edinburgh's School of Law, spoke at the conference, each delivering a presentation on the governance issues arising out of delivering health care and operating in increasingly cross border

\footnotetext{
1 “EAHL 2015” (2015) available at http://www.eahl2015prague.eu/ (accessed 23 Oct 15).
} 
settings. ${ }^{2}$ In the first session of the conference Nayha Sethi, Deputy Director of the Mason Institute and Research Fellow for the Farr Institute Scotland, delivered a talk on interoperability in data sharing across sectors. Her presentation focused on the barriers and facilitators of interoperability that were revealed in research undertaken with colleagues which engaged relevant stakeholders involved in the research use of data across the UK (and across sectors). ${ }^{3}$ I also presented, in my capacity as Research Fellow for the Administrative Data Research Centre Scotland, on the crucial role of good governance in reducing risk and minimising harm when individuals' personal (or even anonymised) data are used. ${ }^{4}$ My presentation was delivered on the basis of an evidence review undertaken with colleagues Professor Graeme Laurie, Dr Christine Dobbs and Dr Kerina Jones for the Nuffield Council on Bioethics and Wellcome Trust's Expert Advisory Group on Data Access which sought evidence of harm arising out of the use of health and biomedical data. ${ }^{5}$ After both presentations, discussion with the delegates in attendance focussed on the role of the law and understanding its limits in guiding proportionate yet robust approaches to information governance which are protective of individuals' rights yet facilitative of public interest uses of data.

Dr Shawn Harmon, Deputy Director of the Mason Institute and Lecturer in Risk and Regulation at the University of Edinburgh and Dr Carol George, Post-Doctoral Research Fellow, each spoke to aspects of their involvement with the establishment of the European Bank for induced Pluripotent Stem Cells (EBiSC). ${ }^{6}$ Dr Harmon presented on the practical legal and ethical issues arising out of the establishment of EBiSC, revealing great fragmentation in the applicable regulatory frameworks which problematically injects uncertainty into cross border efforts. Dr Carol George presented on day two of the conference on the broader, theoretical issues at stake in the facilitation of cross border research in context with her work for EBiSC. Dr George's presentation revealed the many conceptual borders that have been (and have yet to be) crossed in creating novel governance structures capable of spanning not only international borders, but the the borders between private and public sectors in a climate of increasing sensitivity to patient's privacy and data and rapid developments in biomedical technology.

Overall, EAHL 2015 afforded delegates a unique opportunity to consider the fundamental aspects of delivering cross border health care from the crucial

\footnotetext{
${ }^{2}$ The J Kenyon Mason Institute for Medicine, Life Science and the Law is an interdisciplinary network based in the Edinburgh Law School at the University of Edinburgh. Available at http://masoninstitute.org/ (accessed 23 Oct 15).

3 “Farr Institute@ Scotland" available at http://www.farrinstitute.org/centre/Scotland/3 About.html (accessed 23 Oct 15).

4 “Administrative Data Research Centre Scotland" available at http://adrn.ac.uk/centres/scotland (accessed 23 Oct 15).

${ }^{5}$ G Laurie, K Jones, L Stevens and C Dobbs "A Review of Evidence Relating to Harm Resulting from Uses of Health and Biomedical Data" (2014) available at http://nuffieldbioethics.org/wpcontent/uploads/A-Review-of-Evidence-Relating-to-Harms-Resulting-from-Uses-of-Health-andBiomedical-Data-FINAL.pdf (accessed 23 Oct 15).

6 “EBiSC" available at http://www.ebisc.org/ (accessed 23 Oct 15).
} 
perspectives of Member States, regulators and patients, all in light of recent developments and the impact of regulation in this field. Most importantly, delegates were able to critically engage with the lessons learned from other countries' experiences in hopes of identifying potential solutions for the betterment of patient care and benefit to the broader public interests at stake. 